\title{
Health Status and Access to Health Care Among D/deaf and Hard-of-Hearing Canadians
}

\author{
Laura M. Kinlin \\ Class of 2013, Faculty of Medicine, Dalhousie University
}

$\mathrm{C}$ ommunication has long been recognized as an important part of healthcare provision, from the initial capture of a patient history to instructions for follow-up. As the medical profession moves toward a model of truly patient-centered care, the need for effective communication becomes even more critical. There are certain populations, however, for whom communication between physician and patient is inherently challenging. ${ }^{1}$ One such population is the D/deaf and hard-of-hearing community. This brief review summarizes some of the barriers that may limit access to health care for these individuals. Differences in healthcare utilization and health status in a Canadian context are also presented, along with a discussion of accommodations that have been suggested to improve quality of care.

In any such discussion it should be recognized that the D/deaf and hard-of-hearing constitute a heterogenous population. Based on both communication preferences and needs, three general but distinct categories can be defined $^{2}:$ 1) hard-of-hearing individuals who use verbal communication; 2) deaf individuals who use verbal communication; and 3) Deaf individuals who use sign language and identify with Deaf culture, including social conventions and the belief that deafness is not a disability (Deaf, written with an upper case 'D', is widely used to denote cultural Deafness). In this review, barriers and accommodations specific to the hard-of-hearing and deaf are briefly outlined; however, there is a particular focus on the Deaf community, the group for whom communication and access to quality health care are likely to be the most challenging.

Healthcare Utilization, Knowledge and Outcomes among D/deaf and Hard-of-Hearing Individuals

Relatively little is known about the health of $\mathrm{D} /$ deaf and hard-of-hearing Canadians. In order to help fill this gap, Woodcock and Pole ${ }^{3}$ used data from the 2000/2001 Canadian Community Health Survey (CCHS) to explore the prevalence of hearing problems and the general health of affected individuals. They estimated that $4 \%$ of the population in Canada has hearing loss sufficient to prevent communication in groups if hearing aids are not used. Prevalence was found to increase with age, and was marginally higher in males than females $(4.52 \%$ versus $3.53 \%)$. In the United States, hearing loss is known to be the sixth most common chronic health condition, ${ }^{4}$ affecting approximately $9 \%$ of the population. ${ }^{5}$ Rates are higher (at approximately 24\%) among older residents in long-term care facilities. ${ }^{6}$

The CCHS data indicate that D/deaf and hard-ofhearing Canadians have a higher rate of primary care consultations (odds ratio [OR] relative to hearing individuals, 1.52; 95\% confidence interval [95\% CI], 1.35 - 1.71). ${ }^{3}$ However, these individuals report lower self-perceived general health status (OR, 0.54; 95\% CI, $0.49-0.60)$ and are more likely to report unmet healthcare needs (OR, 1.31; 95\% CI, 1.17 - 1.46). These results are consistent with numerous American studies, which describe increased use of physicians' services but lower satisfaction with both healthcare quality and access. ${ }^{7-9}$ It has been hypothesized that this relationship could be due to repeat visits in which patients are trying to resolve uncertainties created by communication barriers. ${ }^{3,9}$

Based on the CCHS data, ${ }^{3}$ Canadians who are D/deaf and hard-of-hearing also appear to have higher rates of certain health conditions. These include heart disease (OR, 1.31; 95\% CI, 1.17 - 1.48) and depression (OR, 1.59; $95 \%$ CI, $1.36-1.85)$. Although significantly less likely to smoke or drink, D/deaf and hard-of-hearing individuals were more likely to be physically inactive (OR, 1.14; 95\% CI, 1.01 - 1.29) and obese (OR, 1.27; 95\% CI, 1.09 1.48). The likelihood of having undergone mammogram and Pap screening was similar between those with and without hearing loss.

In interpreting these data there are several methodological limitations that should be noted, however. First, because of the nature of the CCHS questions, it was not possible to differentiate between $\mathrm{D} /$ deaf and hard-of-hearing respondents. As such, health outcomes, behaviours, and healthcare utilization could not be explored based on the degree or timing (i.e., prelingual or postlingual) of hearing loss. Second, CCHS responses were based on self-reported hearing status, rather than on objective 
measurement of hearing thresholds. The sensitivity of self-report has been previously found to be low when compared to audiometrically-measured hearing loss. ${ }^{10} \mathrm{~A}$ final limitation is that a sizable proportion (approximately $37 \%$ ) of surveys were conducted via telephone, which may have resulted in the systematic exclusion of D/deaf and hard-of-hearing individuals. The CCHS sampling method and hearing status measurement both suggest that the $4 \%$ prevalence reported by Woodcock and Pole ${ }^{3}$ might be an underestimate. Results from numerous American studies have been substantially higher, with Nash et al. ${ }^{11}$ and Agrawal et al. ${ }^{10}$ recently identifying the prevalence of hearing loss in the United States as 14\% and 16\%, respectively. Additional American studies have explored knowledge and understanding of health promotion issues among those with identified hearing loss. Results have documented, among D/deaf and hard-of-hearing individuals, less knowledge of health issues and less awareness of the importance of preventive medicine. ${ }^{12}$ Information about HIV/AIDS is a particular concern as D/deaf people seem to be less aware of viral transmission and risk factors for infection. ${ }^{13}$ It is thought that this might translate to increased risk and incidence of HIV/AIDS among individuals with hearing loss. ${ }^{13}$

\section{Barriers to Healthcare among D/deaf and Hard- of-Hearing Individuals}

Among D/deaf and hard-of-hearing individuals, the principle barrier to quality healthcare is difficulty in communication related to language. The primary mode of communication in Deaf individuals - American Sign Language (ASL) - is not merely the signed equivalent of English; indeed, it has a unique syntax and grammatical structure. ${ }^{14}$ Facial expression, in addition to hand shape and movement, are extremely important in conveying meaning, including nuances and subtleties. ${ }^{14}$ These ASL-English differences may result in miscommunications with important consequences. Meador and Zazove ${ }^{15}$ cite an example in which a physician wrote, "You may need surgery." The patient, based on ASL sentence structure, interpreted this as needing surgery in the month of May. Research shows that healthcare professionals experience, and are aware of, these barriers in communication. In one survey of 165 physicians, participants reported greater difficulties in understanding $(\mathrm{P}<0.001)$ and maintaining conversations $(\mathrm{P}<0.001)$ with deaf patients relative to hearing patients. ${ }^{16}$ In an interview, one Deaf woman described her perspective as a patient, noting the lack of communication she experienced during her first Pap smear ${ }^{1}$ :

They didn't tell me what they were going to do. There I was in the stirrups - I couldn't see what was going on. The doctor didn't say to me, 'This might be uncomfortable,' or tell me how much pain to expect. I never went again.

In addition to the language barriers described above, there are also related practical barriers that may affect quality of health care. In particular, D/deaf and hard-ofhearing individuals have reported difficulties with booking appointments and interacting with staff. One Deaf patient described the challenges she encounters while at the clinic ${ }^{1}$ :

You can't hear the receptionist. You hope you'll know when they call your name. Then you go into another room, and they tell you to take off some of your clothes, all of your clothes, or none of your clothes. If you get that wrong, you're in trouble. Then you don't hear the doctor at the door. They come in, and you don't know whether you've taken the right clothes off. Each thing seems little in itself. But when it all happens one after the other, you feel very anxious.

A final barrier to healthcare, in some instances, may be a perceived patronizing attitude on the part of the healthcare profession. ${ }^{1,17}$ Some Deaf individuals fear that their intelligence is underestimated because of their hearing loss (as in the much-despised expression "deaf and dumb"). ${ }^{15}$ Reluctance may also come from experiences in which physicians want to "fix" them, although the patient does not view deafness as a disability in need of repair. ${ }^{18}$

\section{Accommodations to Improve Quality of Care and Communication}

It has been suggested that barriers to communication among the D/deaf and hard-of-hearing can be ameliorated with flexibility and the ability to adapt to a given situation. ${ }^{2}$ It is particularly important to ask the patient his or her preference. ${ }^{2}$ One patient stated, "Just ask me, 'How can I best communicate with you?". Different individuals will have different comfort levels and abilities with different strategies, which may depend on the severity of hearing loss and the age at which it occurred (i.e., those who are hard-of-hearing will likely have different communication needs than individuals who are prelingually deaf and communicate primarily using ASL). ${ }^{2}$

If lipreading is used, healthcare professionals should ensure that their faces are well lit and their mouths are not obscured. ${ }^{2}$ They should also be aware that lipreading is a difficult skill to develop and that, at most, 30\% of English words can be read on the lips., ${ }^{2,19}$ It may be particularly difficult in a medical context, with unfamiliar terminology and the possibility of poor lighting and face masks ${ }^{3}$. For 
the hard-of-hearing, in particular, background noise may act as a distraction and detract from the communication process. ${ }^{3}$ The healthcare professional should therefore state the topic explicitly before describing further details. Repetition and occasional summaries may also be useful, in addition to checking occasionally for understanding. ${ }^{2}$

Written communication is often helpful for communication in a medical context, particularly with those who are hard-of-hearing or for deaf people who communicate orally and consider English their primary language. ${ }^{2}$ For Deaf individuals, however, written communication may be problematic. ${ }^{2}$ Because ASL is fundamentally different from English in many respects, the reading level in the Deaf population is lower than in the general population. ${ }^{20-23}$ Physicians should be aware that by asking a Deaf individual to read and write in English, they may effectively be asking him or her to communicate in a second language. ${ }^{24}$

For Deaf individuals who use ASL, an interpreter is generally regarded as the preferred method of facilitating patient-doctor interaction. ${ }^{2}$ The Supreme Court of Canada has ruled that $\mathrm{D} /$ deaf people are entitled to the services of a qualified interpreter in the healthcare system. ${ }^{25}$ If an interpreter is present, the room should be well-lit and the physician should maintain eye contact with the patient. ${ }^{2}$

Several additional "easy" accommodations have also been suggested to improve healthcare and communication quality. For example, if intravenous access is required in a Deaf individual, the line should not be inserted into the hands, thereby allowing the patient to continue signing. ${ }^{26}$ It has also been reported that a physician having even minimal ASL skills is appreciated; it is interpreted as a desire to improve communication and a respect for Deaf culture. ${ }^{27}$ When surveyed, many Deaf women said they would switch to a practitioner who was willing to commit time and effort to ensuring effective communication, even if this change were inconvenient in terms of travel and disruption of care. ${ }^{27}$

\section{Conclusions}

Individuals who are $\mathrm{D} /$ deaf or hard-of-hearing may face barriers in communicating with healthcare professionals and accessing quality care. Canadian data suggest that they have lower levels of self-perceived health and higher rates of certain chronic diseases, despite relatively high primary care consultation. Accommodations, such as the use of qualified interpreters when appropriate, may help to ensure effective communication and equitable healthcare access, while facilitating patient-centered care.

\section{References}

1. Iezzoni L, O’Day B, Killeen M, Harker H. Communiating about health care: Observations from persons who Are Deaf or hard of hearing. Ann Inter Med 2004;140:356-362.

2. Barnett S. Communication with Deaf and hard-of-hearing people: A guide for medical education. Acad Med 2002;77(7):694-700.

3. Woodcock K, Pole J. Health profile of deaf Canadians: Analysis of the Canada Community Health Survey. Can Fam Physician 2007;53:21402141.

4. Collins J. Prevalence of selected chronic conditions: United States, 19901992. Vital and Health Statistics 1997;194:1-89.

5. Ries P. Prevalence and characteristics of persons with hearing trouble: United States, 1990-91. Vital and Health Statistics 1994;188:1-75.

6. Gabrel C. Characteristics of elderly nursing home current residents and discharges: Data from the 1997 National Nursing Home Survey. Advance data from Vital and Health Statistics, No. 312. Hyattsville, MD: National Center for Health Statistics, 2000.

7. Barnett S, Franks P. Healthcare utilization and adults who are deaf: Relationship with age at onset of deafness. Health Serv Res 2002;37:105120.

8. Kurz S, Haddock C, Van Winkle D, Wang G. The effects of hearing impairment on health services utilization. Med Care 1991;29:878-879.

9. Zazove P, Niemann L, Gorenflo D, Carmack C, Mehr D, Coyne J, Antonucci T. The health status and health care utilization of Deaf and hard-of-hearing persons. Arch Fam Med 1993;2:745-752.

10. Agrawal Y, Platz EA, Niparko JK. Prevalence of hearing loss and differences by demographic characteristics among US adults: data from the National Health and Nutrition Examination Survey, 1999-2004. Arch Intern Med 2008;168(14):1522-1530.

11. Nash SD, Cruickshanks KJ, Klein R, Klein BE, Nieto FJ, Huang GH, Pankow JS, Tweed TS. The prevalence of hearing impairment and associated risk factors: the Beaver Dam offspring study. Arch Otolaryngol - Head Neck Surg 2011;137(5):432-439.

12. Tamaskar P, Malia T, Stern C, Gorenflo D, Meador H, Zazove P. Preventive attitudes and beliefs of Deaf and hard-of-hearing individuals. Arch Fam Med 2000;9:518-525.

13. Bat-Chava Y, Martin D, Kosciw. Barriers to HIV/AIDS knowledge and prevention among deaf and hard of hearing people. AIDS Care 2005;17(5):623-634.

14. Sacks O. Seeing Voices: A voyage into the world of the Deaf. New York: Vintage Books, 1989.

15. Meador H, Zazove P. Health care interactions with Deaf culture. J Am Board Fam Pract 2005;18(3):218-222.

16. Ralston E, Zazove P, Gorenflo D. Physicians' attitudes and beliefs about deaf patients. J Am Board Fam Pract 1996;9(3):167-173.

17. Lieu C. Communication strategies for nurses interacting with deaf patients. MEDSURG Nursing 2007;16(4):239-244.

18. Padden C, Humphries T. Deaf in America: Voices from a culture. Cambridge, MA: Harvard University Press, 1988.

19. Ebert D, Heckerling P. Communication with Deaf patients: Knowledge, beliefs, and practices of physicians. JAMA 1995;273(3):227-229.

20. Holt J. Stanford Achievement Test - 8th edition: reading comprehension subgroup results. Am Ann Deaf 1993;138:172-175.

21. Parault SJ, Williams HM. Reading motivation, reading amount, and text comprehension in deaf and hearing adults. Jnl of Deaf Studies and Deaf Education 2010;15(2):120-135.

22. Traxler C. The Stanford Achievement Test, 9th Edition: National norming and performance standards for Deaf and hard-of-hearing students. Jnl of Deaf Studies and Deaf Education 2000;5(4):337-348.

23. Luckner JL, Sebald AM, Cooney J, Young J. An examination of the evidence-based literacy research in Deaf education. Am Ann Deaf 2005/2006;150(5):442-456.

24. McEwen E, Anton-Culver H. The medical communiation of deaf patients. J Fam Pract 1988;26:289-291.

25. Eldridge v. British Columbia (Attorney General). 3 S.C.R. 624 (S.C.C.), 1997.

26. McAleer M. Communicating effectively with deaf patients. Nurs Stand 2006;20(19):51-54.

27. Steinberg A, Wiggins E, Barmada C, Sullivan V. Deaf Women: Experiences and perceptions of healthcare system access. J Women's Health 2002;11(8):729-741. 